\title{
Rate of malignancy for thyroid nodules with AUS/FLUS cytopathology in a tertiary care center - a retrospective cohort study
}

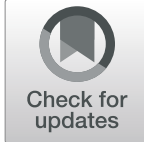

Kalpesh Hathi', Tarek Rahmeh ${ }^{1}$, Vicki Munro ${ }^{1,3}$, Victoria Northrup ${ }^{1,2}$, Ali Sherazi ${ }^{2}$ and Christopher J. Chin ${ }^{1,4^{*}}$ (D

\begin{abstract}
Background: Thyroid nodules are stratified through fine-needle aspiration (FNA) and are often categorized using The Bethesda System for Reporting Thyroid Cytopathology, which estimates the risk of malignancy for six cytopathological categories. The atypia of undetermined significance (AUS) and follicular lesion of undetermined significance (FLUS) categories have varying malignancy rates reported in the literature which can range from 6 to 72.9\%. Due to this heterogeneity, we assessed the malignancy rate and effectiveness of repeat FNA (rFNA) for AUS/ FLUS thyroid cytopathology at our institution.

Methods: Electronic health records of patients with AUS/FLUS thyroid cytopathology on FNA at our center since the implementation of the Bethesda System on May 1, 2014-December 31, 2019 were retrospectively reviewed. Patient demographics, treatment pathway, and pathology results were collected. The treatment pathway of the nodules, the rFNA results, and the malignant histopathology results were reported. Malignancy rates were calculated as an upper and lower limit estimate.
\end{abstract}

Results: This study described 182 AUS/FLUS thyroid nodules from 177 patients. In total, 24 thyroid nodules were deemed malignant upon histopathology, yielding a final malignancy rate of $13.2-25.3 \%$. All of the malignancies were variants of papillary thyroid carcinoma. The malignancy rate of the nodules which underwent resection without rFNA (21.5\%) was lower than the malignancy rate of the nodules which underwent resection after rFNA (43.8\%). $45.5 \%$ of the rFNA results were re-classified into more definitive categories.

Conclusion: The malignancy rate of AUS/FLUS thyroid cytopathology at our center is in line with the risk of malignancy stated by the 2017 Bethesda System. However, our malignancy rate is lower than some other Canadian centers and approximately half of our rFNAs were re-classified, highlighting the importance of establishing center-specific malignancy and $\mathrm{rFNA}$ re-classification rates to guide treatment decisions.

Keywords: Thyroid, Bethesda, AUS/FLUS, Nodule, Cytopathology, FNA, Malignancy rate

\footnotetext{
* Correspondence: Christopher.Chin@dal.ca

'Dalhousie Medicine New Brunswick, 711 Millidge Avenue, Suite A, Saint John, NB E2K 2N7, Canada

${ }^{4}$ Department of Surgery, Division of Otolaryngology - Head \& Neck Surgery, Dalhousie University, Halifax, Nova Scotia, Canada

Full list of author information is available at the end of the article
}

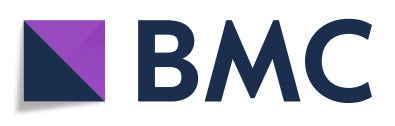

(- The Author(s). 2021 Open Access This article is licensed under a Creative Commons Attribution 4.0 International License, which permits use, sharing, adaptation, distribution and reproduction in any medium or format, as long as you give appropriate credit to the original author(s) and the source, provide a link to the Creative Commons licence, and indicate if changes were made. The images or other third party material in this article are included in the article's Creative Commons licence, unless indicated otherwise in a credit line to the material. If material is not included in the article's Creative Commons licence and your intended use is not permitted by statutory regulation or exceeds the permitted use, you will need to obtain permission directly from the copyright holder. To view a copy of this licence, visit http://creativecommons.org/licenses/by/4.0/. The Creative Commons Public Domain Dedication waiver (http://creativecommons.org/publicdomain/zero/1.0/) applies to the data made available in this article, unless otherwise stated in a credit line to the data. 


\section{Background}

The incidence of thyroid cancer continues to increase in Canada and globally [1-4]. Palpation can detect a thyroid nodule in approximately $4 \%$ of the general population $[1,5]$, however ultrasonography can detect nodules in $19-67.6 \%$ of the population $[1,6-8]$. Thyroid nodules have been reported in up to $64.6 \%$ of autopsies $[1,9]$. The more frequent usage of advanced medical imaging has resulted in an increased number of thyroid nodules found incidentally, which is hypothesized to partially account for the increased incidence of thyroid cancer [14]. Despite this increased incidence, the prognosis of thyroid cancer remains highly favorable, with an overall five-year survival rate of $98 \%$ in Canada [2, 3].

Fine-needle aspiration (FNA) is a safe, accurate and cost-effective procedure used to assess thyroid cytopathology and risk of malignancy (ROM) [10]. The Bethesda System for Reporting Thyroid Cytopathology has reduced ambiguity surrounding thyroid FNA results, subsequently decreasing the rate of unnecessary thyroidectomies [11, 12]. The Bethesda System separates thyroid cytopathology into six categories and for each category, the "usual management" and ROM is provided [11]. The management of the atypia of undetermined significance/follicular lesion of undetermined significance (AUS/FLUS) category has been challenging due to its indeterminant nature and heterogeneous reports of malignancy rates $[13,14]$. The original Bethesda System states a ROM of $\sim 5-15 \%$ for this category, and repeat FNA (rFNA) is recommended [11]. However, various institutions have reported widely ranging malignancy rates from 6 to $72.9 \%$ [13-16].

In 2016, histopathology of non-invasive encapsulated follicular variant of papillary thyroid carcinoma (NEFV-PTC) was re-classified as non-invasive follicular thyroid neoplasm with papillary-like nuclear features (NIFTP) to represent its indolent nature [17]. The updated 2017 Bethesda System states a 6-18\% ROM for the AUS/FLUS category when NIFTP is not considered malignant, and a 10-30\% ROM when NIFTP is considered malignant [18]. The $2017 \mathrm{Be}-$ thesda System recommends rFNA, molecular testing, or lobectomy for AUS/FLUS nodules [18].

Despite this update, there is heterogeneity in malignancy rates amongst Canadian centers and between centers in Canada and the United States [19-22]. Due to this lack of consensus, it is important to determine malignancy rates specific to populations of interest [19, 22, 23].

This study assesses the institution-specific malignancy rate and the effectiveness of rFNA for thyroid nodules with AUS/FLUS cytopathology at the Saint John Regional Hospital in Saint John, New Brunswick, the province's largest tertiary care centre with a catchment area serving a population of $\sim 170,000[24,25]$. To the best of our knowledge this is the first study outlining AUS/
FLUS thyroid cytopathology malignancy rate and treatment in New Brunswick, Canada. The results from our center add to the variable literature surrounding AUS/ FLUS thyroid cytopathology and are discussed in relation to reported malignancy rates, specifically in a Canadian context.

\section{Methods}

Approval for retrospective data collection was obtained from the Horizon Health Network Research Ethics Board. All thyroid FNA results since the implementation of the Bethesda System in May 1, 2014-December 31, 2019 were screened, and all patients during this period who were $\geq 18$ years old at the time of FNA and had AUS/FLUS thyroid cytopathology were included in the study.

Electronic health records were retrospectively reviewed. The patients' biological sex, age at the time of first AUS/FLUS cytopathology result, treatment pathway, and pathology results were collected. A nodule was deemed malignant or benign based on surgical histopathology only. Histopathology was correlated to the nodule targeted by FNA by associating the location and size of the nodule. A sub-centimeter microcarcinoma not targeted by the FNA and not found within a larger nodule targeted by FNA was defined as incidental. The presence of an incidental microcarcinoma was noted but deemed benign for the purpose of this study. NIFTP/ NEFV-PTC histopathology was considered malignant in this study as the inclusion period pre-dated the 2016 nomenclature and classification adjustment [17].

FNA cytopathology and surgical histopathology were reviewed by in-house pathologists. A specialist in Head and Neck pathology external to our institution was consulted in challenging cases. Final treatment decision making was in collaboration between the patient and the treating physicians. Unless more concerning features were present, AUS/FLUS surgical patients were referred for lobectomy, and if a thyroid carcinoma was identified, contralateral completion thyroidectomy was recommended.

\section{Data analysis}

The proportion of all thyroid FNAs which were classified as AUS/FLUS was calculated. The treatment pathway of the AUS/FLUS thyroid nodules and the distribution of rFNA results were described as percentages. If multiple rFNAs were performed for the same nodule, the most definitive rFNA result was reported. The malignancy rate was calculated for the nodules which underwent immediate resection and those which underwent resection after rFNA. Finally, the distribution of malignant histopathology was calculated.

The final malignancy rate was calculated as an upper limit estimate (ULE) and a lower limit estimate (LLE), as described by Ho et al. [23]. The ULE was the malignancy 
rate of the resected nodules. The LLE was calculated under the assumption that all the unresected nodules were benign, and therefore was a malignancy rate of all AUS/FLUS cytopathology results.

\section{Results}

During our inclusion period 1130 thyroid FNAs were performed at our center, of which 205 (18.1\%) yielded AUS/FLUS cytopathology, 23 of which were rFNA results of previously categorized AUS/FLUS nodules and thus were not included as separate nodules. A total of 182 thyroid nodules with AUS/FLUS cytopathology from 177 patients were included in this study. The patients had a mean age of $58.5+/-15.5$ years at the time of the AUS/FLUS cytopathology result. The majority of the patients $(74.6 \%$, or $n=132)$ were female. $25.4 \%(n=45)$ were male.

The treatment pathway of the AUS/FLUS thyroid nodules is described in Fig. 1. Of the 182 nodules, 44 (24.2\%) underwent rFNA, 79 (43.4\%) underwent resection, and 59 (32.4\%) were followed clinically and had no further pathology results available. 16/44 (36.4\%) of the nodules which underwent rFNA were resected, and 7/16 (43.8\%) of these were malignant. In contrast, 17/79 (21.5\%) of the nodules which were resected without rFNA were malignant. The majority of AUS/FLUS surgical patients $(84.4 \%)$ underwent initial lobectomy.

In total 95/182 (52.2\%) of the AUS/FLUS nodules were eventually resected, with 24/95 (25.3\%) of these nodules yielding malignant histopathology, representing the ULE malignancy rate. 24/182 (13.2\%), represents the LLE malignancy rate.

Table 1 represents the results of the 44 rFNAs, $45.5 \%$ were re-classified into more definitive categories, whereas $54.5 \%$ remained indeterminant (AUS/FLUS or non-diagnostic). The most common rFNA result was AUS/FLUS (36.4\%) and the most common rFNA reclassification result was benign (25.0\%).

Table 2 represents the histopathology reported from the 24 malignant outcomes. All were variants of papillary thyroid carcinoma (PTC). Three (12.5\%) were subcentimeter papillary thyroid microcarcinomas (PTMC) which were either targeted by the FNA or were found within a larger nodule which was targeted by the FNA. Incidental PTMCs were present in 14 (14.7\%) of the resected specimens, 5 (5.3\%) were found alongside macro-carcinomas in the indexed nodule, and 9 (9.5\%) did not have a macro-carcinoma present and were categorized as benign (Table 3 ).

\section{Discussion}

The Bethesda System for Reporting Thyroid Cytopathology effectively standardizes categorization of thyroid FNA results $[12,18]$. However, the indeterminate nature of AUS/FLUS cytopathology has resulted in heterogeneous reports of malignancy rates for this category [13, 14]. The malignancy rate of AUS/FLUS thyroid cytopathology at our center is $13.2-25.3 \%$.

Many centers report malignancy rates above the 5-15\% ROM stated by the 2009 Bethesda System (Table 4) [11, 13, 14, 16, 19-23, 26-33]. The 2017 Bethesda System states a

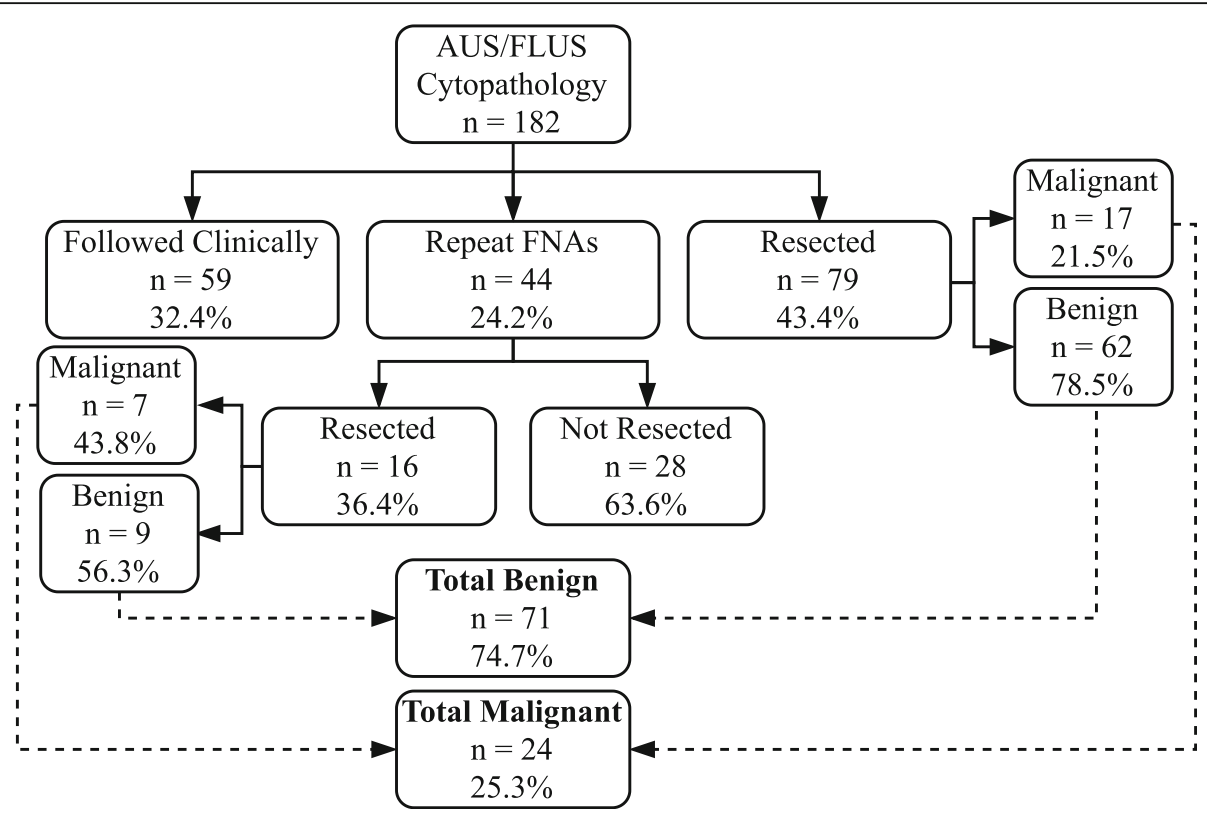

Fig. 1 Treatment pathway of the thyroid nodules with AUS/FLUS cytopathology at our center. Abbreviations: FNA - fine needle aspiration; AUS/ FLUS - atypia of undetermined significance/follicular lesion of undetermined significance 
Table 1 Results of the 44 rFNAs after initial AUS/FLUS cytopathology result

\begin{tabular}{|c|c|c|c|c|c|}
\hline Classification & $N=(\%)$ & rFNA Result & Frequency (\%) & Resected $\left(\%^{a}\right)$ & Malignant $\left(\%^{\mathbf{b}}\right)$ \\
\hline \multirow[t]{2}{*}{ Indeterminant } & $24(54.5 \%)$ & AUS/FLUS & 16 (36.4\%) & $6(37.5 \%)$ & $2(33.3 \%)$ \\
\hline & & Non-Diagnostic & $8(18.2 \%)$ & $2(25.0 \%)$ & $0(0 \%)$ \\
\hline \multirow[t]{4}{*}{ Re-Classified } & $20(45.5 \%)$ & Benign & $11(25.0 \%)$ & $1(9.1 \%)$ & $0(0 \%)$ \\
\hline & & FN/SFN & $5(11.4 \%)$ & $3(60.0 \%)$ & 1 (33.3\%) \\
\hline & & SFM & $4(9.1 \%)$ & $4(100.0 \%)$ & $4(100.0 \%)$ \\
\hline & & Malignant & $0(0 \%)$ & N/A & N/A \\
\hline
\end{tabular}

Abbreviations: AUS/FLUS atypia of undetermined significance/follicular lesion of undetermined significance, FN/SFN follicular neoplasm/suspicious for follicular neoplasm, SFM suspicious for malignancy

${ }^{\text {a }}$ Percent of frequency

${ }^{b}$ Percent of resected

10-30\% ROM for AUS/FLUS thyroid cytopathology [18] which coincides well with our malignancy rate (13.2-25.3\%). However, centers do report malignancy rates exceeding 30\% (Table 4) [16, 19-21, 33].

In terms of Canadian data, the malignancy rate seems to vary geographically. The largest Canadian series of AUS/FLUS thyroid cytopathology was conducted in an Ontario center and yielded a $37-46 \%$ malignancy rate [19], which is noticeably higher than our center. A study in Newfoundland also reported a higher LLE malignancy rate of 29.8\% [20]. However, centers in Western Canada [21] and Nova Scotia [22] reported ULE malignancy rates of 32 and $24.7 \%$ respectively, which are similar to our study. Overall, our malignancy rate is within the lower end of those reported in the literature (Table 4).

These higher malignancy rates may suggest the need for further adjustment of the ROM stated in the 2017 Bethesda System. However, it is also possible that there is no generalizable ROM for this cytopathology [34]. Rather, center and population specific factors may account for the variability of malignancy rates [19, 22, 23]. For example, Ho et al., [23] noted their higher malignancy rate $(26.6-37.8 \%)$ may be attributed to their high volume

Table 2 Histopathology of 24 malignancies from thyroid nodules with AUS/FLUS cytopathology

\begin{tabular}{ll}
\hline Histopathology & Frequency (\% of malignant) \\
\hline FV-PTC & $13(54.2 \%)$ \\
Classic-PTC & $4(16.7 \%)$ \\
PTMC & $3(12.5 \%)$ \\
NIFTP & $2(8.3 \%)$ \\
TCV-PTC & $1(4.2 \%)$ \\
Oncocytic-PTC & $1(4.2 \%)$ \\
\hline
\end{tabular}

Abbreviations: FV-PTC follicular variant of papillary thyroid carcinoma, ClassicPTC classic or not specified variant of papillary thyroid carcinoma, PTMC papillary thyroid microcarcinoma, NIFTP non-invasive follicular thyroid neoplasms with papillary-like nuclear features, TCV-PTC tall cell variant of papillary thyroid carcinoma, Oncocytic-PTC oncocytic variant of papillary thyroid carcinoma cancer center setting, potentially resulting in a referral bias of more concerning nodules. Conversely, Cavalheiro et al. [26] reported a $15.7 \%$ malignancy rate from a center where all AUS/FLUS thyroid nodules were surgically resected and $\mathrm{Wu}$ et al. [15] reported a 6\% malignancy rate for FNAs from community practice settings. As shown in these studies, there is a wide variability in the malignancy rate for this cytological diagnosis, and this illustrates the importance and value of identifying the malignancy rate at ones' own institution.

Our center had a high rate of AUS/FLUS diagnosis (18.1\%) compared to the Bethesda recommendation of $\leq 10 \%$ [18]. The common "overuse" of the category and the greater inter-/intra-observer variability of AUS/ FLUS diagnosis has been noted [13]. The other Canadian center with a similar malignancy rate to this study also reported a high AUS/FLUS rate (18.8\%) [22], whereas the two Canadian centers with higher malignancy rates had lower AUS/FLUS rates (5.5 and 12.0\% respectively) $[19,20]$. This relationship is observed in many studies cited in Table 4, and it is likely that lower AUS/FLUS rates correspond to higher malignancy rates. It has been hypothesized that higher AUS/FLUS rates (> $15 \%)$ result in more benign or non-diagnostic cases categorized as AUS/FLUS, whereas lower rates $(<5 \%)$ are associated with reduced sensitivity [13, 35], which is important knowledge for clinical decision making.

The Bethesda System recommends lobectomy, rFNA, or molecular testing for AUS/FLUS cytopathology [18]. At our center, the malignancy rate of nodules resected after rFNA (43.8\%) was noticeably higher than those proceeding directly to surgery (21.5\%). This can likely be

Table 3 Description of 14 incidental microcarcinomas

\begin{tabular}{ll}
\hline Histopathology & Frequency (\% of resected) \\
\hline With Macro-Carcinoma (Malignant) & $5(5.3 \%)$ \\
Without Macro-Carcinoma (Benign) & $9(9.5 \%)$ \\
Total & $14(14.7 \%)$ \\
\hline
\end{tabular}


Table 4 Malignancy rate of AUS/FLUS thyroid cytopathology reported at various centers

\begin{tabular}{|c|c|c|c|c|c|}
\hline Series & Country & Period & AUS/FLUS Rate $\%$ & LLE Malignancy Rate \% & ULE Malignancy Rate $\%$ \\
\hline Present Study & Canada & 2014-19 & $18.1(205 / 1130)$ & $13.2(24 / 182)$ & $25.3 \%(24 / 95)$ \\
\hline The Bethesda System [11] & N/A & 2009 & $\leq 7$ & $\sim 5-15$ & N/A \\
\hline The Bethesda System [18] & N/A & 2017 & $\leq 10$ & 10-30 & N/A \\
\hline Bernstein et al. [19] & Canada & 2010-13 & 12.0 & $37(86 / 233)$ & $46(86 / 187)$ \\
\hline Erivwo \& Ghosh [20] & Canada & 2010-13 & 5.5 & $29.8(54 / 181)$ & $\mathrm{N} / \mathrm{A}$ \\
\hline Oosthuizen et al. [21] & Canada & 2010-16 & N/A & N/A & $32(30 / 93)$ \\
\hline Williams et al. [22] & Canada & $2006-10$ & 18.8 & N/A & $24.7(\mathrm{~N} / \mathrm{A})$ \\
\hline Wu et al. [15] & United States & $2006-08$ & 27.2 & N/A & $6(3 / 51)$ \\
\hline Hong et al. [16] & South Korea & 2011-14 & N/A & $10.2(70 / 687)$ & $72.9(70 / 96)$ \\
\hline Ho et al. [23] & United States & 2008-11 & 8.0 & $26.6(144 / 541)$ & $37.8(144 / 381)$ \\
\hline Cavalheiro et al. [26] & Brazil & 2010-14 & N/A & N/A & $15.7(75 / 478)$ \\
\hline Mileva et al. [27] & Republic of Macedonia & $2012-16$ & 5.9 & N/A & $31.2(35 / 112)^{a}$ \\
\hline Al-Abbadi et al. [28] & Saudi-Arabia & 2010-14 & 4.4 & N/A & $29(12 / 42)^{a}$ \\
\hline Wong et al. [29] & United States & $2008-12$ & 9 & N/A & $33.1(60 / 181)$ \\
\hline Yaprak Bayrak et al. [30] & Turkey & $2012-17$ & 4.2 & N/A & $25.0(27 / 108)$ \\
\hline Sullivan et al. [31] & United States & $2003-12$ & 6 & $17(56 / 332)$ & $33(56 / 168)$ \\
\hline Topaloglu et al. [32] & Turkey & N/A & $\mathrm{N} / \mathrm{A}$ & N/A & $23.4(105 / 449)$ \\
\hline Vanderlaan et al. [33] & United States & 2005-09 & 10.9 & $29.0(96 / 331)^{a}$ & $48.2(96 / 199)$ \\
\hline
\end{tabular}

Abbreviations: AUS/FLUS atypia of undetermined significance/follicular lesion of undetermined significance, LLE lower limit estimate, ULE upper limit estimate ancludes malignant/benign diagnosis based on histopathology, core needle biopsy, or rFNA

attributed to nodules re-classified in more concerning categories (FN/SFN and SFM) representing $43.8 \%$ of the resections after rFNA. In contrast, the majority of nodules re-classified by rFNA yielded benign cytopathology (25.0\%) and only one was resected. This is in line with previous studies [31,36], and demonstrates the potential for rFNA to facilitate management of nodules originally classified as AUS/FLUS. However, varying rFNA reclassification rates are reported amongst Canadian centers $[36,37]$, suggesting value in determining the institutional rFNA re-classification rates.

This study has some limitations. Due to its retrospective nature, $52.2 \%$ of the thyroid nodules with AUS/FLUS cytopathology underwent surgical resection, while the remaining nodules lacked histopathology results and were not definitively classified as benign or malignant. They were assumed to be benign when calculating the LLE malignancy rate, however it is possible they contained an indolent, malignant neoplasm. Also, the number of rFNAs which underwent resection is small and a larger sample size would be required to provide stronger conclusions for this sub-group. Finally, this study considered NIFTP/NEFV-PTC histopathology as malignant due to the inclusion period pre-dating our institution's implementation of the 2016 nomenclature change [17]. A future study comparing the malignancy rate pre and post implementation of NIFTP nomenclature at our center would be of interest.

\section{Conclusion}

The malignancy rate of thyroid nodules with AUS/FLUS cytopathology at our center is $13.2-25.3 \%$. Our malignancy rate is in line with the ROM stated by the Bethesda System $(\sim 10-30 \%)$ [18]. Repeat FNA was helpful in re-classifying nearly $50 \%$ of the nodules that were biopsied and remains a useful technique in triaging these nodules. This study highlights the importance of establishing center-specific malignancy and rFNA reclassification rates to guide treatment decisions.

\section{Abbreviations}

FNA: Fine-needle aspiration; ROM: Risk of malignancy; AUS: Atypia of undetermined significance; FLUS: Follicular lesion of undetermined significance; rFNA: Repeat fine-needle aspiration; NEFV-PTC: Non-invasive encapsulated follicular variants of papillary thyroid carcinoma; NIFTP: Noninvasive follicular thyroid neoplasms with papillary-like nuclear features; ULE: Upper limit estimate; LLE: Lower limit estimate; FN: Follicular neoplasm; SFN: Suspicious for a follicular neoplasm; SFM: Suspicious for malignancy; PTC: Papillary thyroid carcinoma; PTMC: Papillary thyroid microcarcinoma; FVPTC: Follicular variant of papillary thyroid carcinoma; Classic-PTC: Classic or not otherwise specified variant of papillary thyroid carcinoma; TCV-PTC: Tall cell variant of papillary thyroid carcinoma; Oncocytic-PTC: Oncocytic variant of papillary thyroid carcinoma

\section{Acknowledgements}

Not applicable.

\section{Authors' contributions}

$\mathrm{KH}$ completed data collection and drafted the manuscript. TR, VM, and CJC designed the study, assisted in interpreting the results, and helped prepare and revise the manuscript. VN and AS facilitated data collection and helped revise the manuscript. All authors read and approved the final manuscript. 


\section{Funding}

No funding was received for this study.

\section{Availability of data and materials}

The datasets used and analysed during the current study are available from the corresponding author upon reasonable request and approval from the Horizon Health Network Privacy Officer.

\section{Declarations}

\section{Ethics approval and consent to participate}

Approval and waiver of consent for retrospective data collection/secondary use of health information was obtained from the Horizon Health Network Research Ethics Board, ROMEO File \#: 100627.

\section{Consent for publication}

Not applicable.

\section{Competing interests}

The authors declare that they have no competing interests.

\section{Author details}

'Dalhousie Medicine New Brunswick, 711 Millidge Avenue, Suite A, Saint John, NB E2K 2N7, Canada. 'Department of Laboratory Medicine, Horizon Health Network, Saint John Regional Hospital, Saint John, NB, Canada. ${ }^{3}$ Department of Medicine, Horizon Health Network, Division of Endocrinology, Saint John Regional Hospital, Saint John, NB, Canada. ${ }^{4}$ Department of Surgery, Division of Otolaryngology - Head \& Neck Surgery, Dalhousie University, Halifax, Nova Scotia, Canada.

Received: 7 September 2020 Accepted: 26 June 2021

Published online: 11 October 2021

\section{References}

1. Dean DS. Epidemiology of thyroid nodules. Best Pract Res Clin Endocrinol Metab. 2008;22(6):901-11.

2. Canadian Cancer Statistics Advisory Committee. Canadian Cancer Statistics 2019. Toronto: Canadian Cancer Society; 2019. cancer.ca/Canadian-CancerStatistics-2019-EN. Accessed 26 Oct 2019

3. Topstad D, Dickinson JA. Thyroid cancer incidence in Canada: a national cancer registry analysis. CMAJ Open. 2017;5(3):E612-6.

4. La Vecchia C, Malvezzi M, Bosetti C, Garavello W, Bertuccio P, Levi F, et al. Thyroid cancer mortality and incidence: a global overview. Int J Cancer. 2015:136(9):2187-95.

5. Vander JB, Gaston EA, Dawber TR. The significance of nontoxic thyroid nodules: final report of a 15-year study of the incidence of thyroid malignancy. Ann Intern Med. 1968;69:537-40.

6. Woestyn J, Afschrift M, Schelstraete K, Vermeulen A. Demonstration of nodules in the normal thyroid by echography. Br J Radiol. 1985;58(696): 1179-82.

7. Reiners C, Wegscheider K, Schicha H, Theissen P, Vaupel R, Wrbitzky R, et al. Prevalence of thyroid disorders in the working population of Germany: ultrasonography screening in 96,278 unselected employees. Thyroid. 2004; 14(11):926-32.

8. Guth S, Theune U, Aberle J, Galach A, Bamberger CM. Very high prevalence of thyroid nodules detected by high frequency $(13 \mathrm{MHz})$ ultrasound examination. Eur J Clin Investig. 2009:39(8):699-706.

9. Hull OH. Critical analysis of two hundred twenty-one thyroid glands; study of thyroid glands obtained at necropsy in Colorado. AMA Arch Pathol. 1955; 59(3):291-311.

10. Gharib H, Goellner JR. Fine-needle aspiration biopsy of the thyroid: an appraisal. Ann Intern Med. 1993;118(4):282-9.

11. Cibas ES, Ali SZ. The Bethesda system for reporting thyroid cytopathology. Thyroid. 2009;19(11):1159-65.

12. Crowe A, Linder A, Omar H, Salih C, Roberson J, Gidley J, et al. The impact of implementation of the Bethesda system for reporting cytopathology on the quality of reporting, "risk" of malignancy, surgical rate, and rate of frozen sections requested for thyroid lesions. Cancer Cytopathol. 2011;119(5):31521.
13. Kholová I, Ludvíková M. Thyroid atypia of undetermined significance or follicular lesion of undetermined significance: an indispensable Bethesda 2010 diagnostic category or waste garbage? Acta Cytol. 2014;58(4):319-29.

14. Straccia P, Rossi ED, Bizzarro T, Brunelli C, Cianfrini F, Damiani D, et al. A meta-analytic review of the Bethesda system for reporting thyroid cytopathology: has the rate of malignancy in indeterminate lesions been underestimated? Cancer Cytopathol. 2015;123(12):713-22.

15. Wu HH, Rose C, Elsheikh TM. The Bethesda system for reporting thyroid cytopathology: an experience of 1,382 cases in a community practice setting with the implication for risk of neoplasm and risk of malignancy. Diagn Cytopathol. 2012;40(5):399-403.

16. Hong SH, Lee H, Cho MS, Lee JE, Sung YA, Hong YS. Malignancy risk and related factors of atypia of undetermined significance/follicular lesion of undetermined significance in thyroid fine needle aspiration. Int J Endocrinol 2018:2018:4521984. https://doi.org/10.1155/2018/4521984.

17. Nikiforov YE, Seethala RR, Tallini G, Baloch ZW, Basolo F, Thompson LDR, et al. Nomenclature revision for encapsulated follicular variant of papillary thyroid carcinoma: a paradigm shift to reduce overtreatment of indolent tumors. JAMA Oncol. 2016:2(8):1023-9.

18. Cibas ES, Ali SZ. The 2017 Bethesda system for reporting thyroid cytopathology. Thyroid. 2017:27(11):1341-6.

19. Bernstein JM, Shah M, MacMillan C, Freeman JL. Institution-specific risk of papillary thyroid carcinoma in atypia/follicular lesion. Head Neck. 2016; 36(10):E1210-5.

20. Erivwo P, Ghosh C. Atypia of undetermined significance in thyroid fineneedle aspirations: follow-up and outcome experience in Newfoundland. Canada Acta Cytol. 2018;62(2):85-92.

21. Oosthuizen JL, Walker B, Todorovic E, Masoudi H, Wiseman SM. The presence of papillary features in thyroid nodules diagnosed as atypia of undetermined significance or follicular lesion of undetermined significance increases cancer risk and should influence treatment. Am J Surg. 2018; 215(5):819-23.

22. Williams BA, Bullock MJ, Trites JR, Taylor SM, Hart RD. Rates of thyroid malignancy by FNA diagnostic category. J Otolaryngol Head Neck Surg. 2013:42(61):1-5

23. Ho AS, Sarti EE, Jain KS, Wang H, Nixon IJ, Shaha AR, et al. Malignancy rate in thyroid nodules classified as Bethesda category III (AUS/FLUS). Thyroid. 2014:24(5):832-9.

24. Statistics Canada: Census Profile, 2016 Census. https://www12.statcan.gc.ca/ census-recensement/2016/dp-pd/prof/details/page.cfm? Lang=E\&Tab= 1\&Geo1=HR\&Code $1=1302 \& G e 02=$ PR\&Code2 $=12 \&$ Data $=$ Count\&SearchText $=$ Zone\%202\%20[Saint20John20area]\&SearchType=Begins\&SearchPR=01\&B1 = All\&TABID=1. 2016. Accessed 15 Aug 2020.

25. Horizon Health Network: Saint John Regional Hospital. https://en.horizonnb. ca/facilities-and-services/facilities/saint-john-regional-hospital.aspx (2020). Accessed 15 Aug 2020

26. Cavalheiro BG, Leite AKN, de Matos LL, Miazaki AP, lentile JM, Kulcsar MAV, et al. Malignancy rates in thyroid nodules classified as Bethesda categories III and IV: retrospective data from a tertiary center. Int J Endocrinol and Metab. 2018;16(1):e12871.

27. Mileva M, Stoilovska B, Jovanovska A, Ugrinska A, Petrushevska G Kostadinova-Kunovska S, et al. Thyroid cancer detection rate and associated risk factors in patients with thyroid nodules classified as Bethesda category III. Radiol Oncol. 2018;52(4):370-6.

28. Al-Abbadi MA, Shareef SQ, Yousef MM, Almasri NM, Mustafa HE, Aljawad $\mathrm{H}$, et al. A follow-up study on thyroid aspirates reported as atypia of undetermined significance/follicular lesion of undetermined significance and follicular neoplasm/suspicious for follicular neoplasm: a multicenter study from the Arabian gulf region. Diagn Cytopathol. 2017;45(11):983-8.

29. Wong LQ, LiVolsi VA, Baloch ZW. Diagnosis of atypia/follicular lesion of undetermined significance: an institutional experience. Cytojournal. 2014;11:23.

30. Yaprak Bayrak B, Eruyar AT. Malignancy rates for Bethesda III and IV thyroid nodules: a retrospective study of the correlation between fine-needle aspiration cytology and histopathology. BMC Endocr Disord. 2020;20(1):1-9.

31. Sullivan PS, Hirschowitz SL, Fung PC, Apple SK. The impact of atypia/ follicular lesion of undetermined significance and repeat fine-needle aspiration: 5 years before and after implementation of the Bethesda system. Cancer Cytopathol. 2014:122(12):866-72.

32. Topaloglu O, Baser H, Cuhaci FN, Sungu N, Yalcin A, Ersoy R, et al. Malignancy is associated with microcalcification and higher AP/T ratio in ultrasonography, but not with Hashimoto's thyroiditis in histopathology in 
patients with thyroid nodules evaluated as Bethesda category III (AUS/FLUS) in cytology. Endocrine. 2016;54(1):156-68.

33. VanderLaan PA, Marqusee E, Krane JF. Usefulness of diagnostic qualifiers for thyroid fine-needle aspirations with atypia of undetermined significance. Am J Clin Pathol. 2011;136(4):572-7.

34. Heller KS. Malignancy rate in thyroid nodules classified as Bethesda category III (AUS/FLUS): is there a correct answer? Thyroid. 2014;24(5):787-8.

35. Renshaw AA. Subclassification of atypical cells of undetermined significance in direct smears of fine-needle aspirations of the thyroid: distinct patterns and associated risk of malignancy. Cancer Cytopathol. 2011;119(5):322-7.

36. Allen L, Al Afif A, Rigby MH, Bullock MJ, Trites J, Taylor SM, et al. The role of repeat fine needle aspiration in managing indeterminate thyroid nodules. J Otolaryngol Head Neck Surg. 2019;48(1):1-5.

37. Jooya A, Saliba J, Blackburn A, Tamilia M, Hier MP, Mlynarek A, et al. The role of repeat fine needle aspiration in the management of indeterminate thyroid nodules. J Otolaryngol Head Neck Surg. 2016;45(1):1-6.

\section{Publisher's Note}

Springer Nature remains neutral with regard to jurisdictional claims in published maps and institutional affiliations.

Ready to submit your research? Choose BMC and benefit from:

- fast, convenient online submission

- thorough peer review by experienced researchers in your field

- rapid publication on acceptance

- support for research data, including large and complex data types

- gold Open Access which fosters wider collaboration and increased citations

- maximum visibility for your research: over $100 \mathrm{M}$ website views per year

At BMC, research is always in progress.

Learn more biomedcentral.com/submissions 